\title{
Furando os Bolsos da Psicologia Social: Experimentações Transgressoras na Docência
}

Piercing the Pockets of Social Psychology: Transgressive Experiments in Teaching

Perforando los Bolsillos de la Psicología Social: Experimentos Transgressores en la Enseñanza

\author{
Alice De Marchi Pereira de Souza \\ Universidade do Estado do Rio de Janeiro (UERJ), Rio de Janeiro, RJ, Brasil
}

\section{Karine Shamash Szuchman}

Universidade Federal do Rio Grande do Sul (UFRGS), Porto Alegre, RS, Brasil

\section{Resumo}

Este artigo surge do convite a uma de suas autoras para o evento "Temas em Debate" de 2019, no qual vicejava a interrogação "O que o presente tem a contribuir para uma determinada psicologia social?". Tal acontecimento encontra outro, em andamento: três professoras trocavam ideias sobre suas práticas docentes em universidades públicas e se deparavam com a mesma questão. A experiência de uma sala de aula mais diversa e multicultural a partir das políticas afirmativas é tomada como campo de análise que movimenta nossa docência em psicologia social e impulsiona esta escrita. Diários de campo e correspondências constituem nossas ferramentas metodológicas. Através de processos de formação e experimentação que apostam na educação como prática de liberdade, almejamos discutir possíveis ampliações e transgressões - tanto das práticas docentes em sala de aula quanto da própria psicologia social transmitida, fazendo jus ao caráter disruptivo, inventivo e conectivo do paradigma ético-estético-político do qual partilhamos.

Palavras-chave: Docência; Transgressão; Psicologia Social; Paradigma Ético-estéticopolítico.

\begin{abstract}
This article emerges from the invitation to one of its authors for the event "Themes in Debate" of 2019, in which the question "What does the present have to contribute to a certain social psychology?" arose. Such an event meets another one, in progress: three teachers exchanged ideas about their teaching practices at public universities and faced the same question. The experience of a more diverse and multicultural classroom based on affirmative policies is taken as an analysis field that mobilizes and moves our teaching in social psychology and drives this writing. Field diaries and correspondences are our methodological tools. Through training and experimentation processes that focus on education as a practice of freedom, we aim to discuss possible transgressions - both in the teaching practices in the classroom and in
\end{abstract}


the transmitted social psychology, living up to the disruptive, inventive and connective character of the ethical-aesthetic-political paradigm that we share.

Keywords: Teaching; Transgression; Social Psychology; Ethical-aesthetic-political paradigm.

\section{Resumen}

Este artículo surge de la invitación a una de sus autoras para el evento "Temas en Debate" de 2019, en el que surgió la pregunta "¿Que tiene el presente para aportar a una determinada psicología social?". Tal evento se encuentra con otro, en curso: tres profesoras intercambiaron ideas sobre sus prácticas docentes en las universidades públicas y se enfrentaron a la misma pregunta. Esta experiencia en clases más diversas y multiculturales, las cuales son guiadas por la implementación de políticas de acción afirmativa, constituye el campo de análisis de la enseñanza en psicología social que impulsa este escrito. Los diarios de campo y la correspondencia intercambiada entre profesoras son las herramientas metodológicas utilizadas. A través de procesos de formación y experimentación que apuestan en la educación como práctica de la libertad, discutimos posibles transgresiones, tanto en las prácticas docentes en la clase, como en la psicología social transmitida, a la altura del carácter disruptivo, inventivo y conectivo del paradigma ético-estético-político que compartimos.

Palabras clave: Enseñanza; Transgresión; Psicología Social; Paradigma Ético-estéticopolítico.

Para Gislei, que nos ensinou a furar os bolsos e inventar outras

psicologias sociais de nossos próprios punhos.

\section{Novas roupagens da universidade hoje}

Estas linhas se iniciam no conluio de dois processos. Um deles foi o convite a uma das autoras deste artigo para o evento "Temas em debate", realizado anualmente pelo Programa de Pós-Graduação em Psicologia Social e Institucional da UFRGS. Neste, as/os doutorandas/os em segundo ano de pesquisa realizam produções textuais em grupo a partir de uma questão proposta pelos organizadores e convidam pesquisadoras/es atuantes nas temáticas trabalhadas para debatê-las conjuntamente de modo a produzir uma nova escrita a partir daí. A pessoa convidada, então, pode desenvolver seu próprio texto impulsionado pela indagação proposta e/ou pelo texto debatido.

O outro processo tratou-se de uma composição entre três professoras em torno da experiência docente em psicologia social em universidades públicas ao longo do ano de 2019: de gerações diferentes, uma delas estava em seu primeiro trabalho como professora, na condição de 
substituta, em Pelotas; outra, no seu primeiro ano como professora adjunta, no Rio de Janeiro ${ }^{1}$; e outra, por fim, em seu derradeiro semestre como professora associada, em Porto Alegre ${ }^{2}$. Estando todas responsáveis por disciplinas da área de psicologia social - e, em especial, que interseccionavam psicologia e educação havíamos começado a trocar ideias sobre planos de ensino, estratégias pedagógicas e modos de avaliar através de e-mails e de um grupo criado em um aplicativo de conversas por celular.

Na edição de 2019 do Temas em Debate, a indagação-provocação foi “Como pode a psicologia social contribuir para pensar o presente?". Complexa por si só, a interrogação foi sagazmente invertida por um grupo de doutorandos: emparceirados a um paradigma éticoestético-político, interessou-lhes pensar como o presente interroga determinada psicologia social. A professora convidada a comentar tal trabalho, por sua vez, encontrou nesta pergunta precisamente a matéria de expressão para as questões que irrompiam no diálogo com as outras duas colegas em nosso trio. Afinal, as experiências de sala de aula no presente vêm convocando a um exercício que é crítico mesmo a uma psicologia social que já é contra-hegemônica, bem como às nossas práticas docentes, as quais passamos a nos perguntar se não estariam reproduzindo ainda, em alguma medida, modelos naturalizados. Cumpre, portanto, narrar minimamente que psicologia social é essa e que presente é esse a que nos referimos.

A universidade pública é outra se a compararmos àquela que encontramos em nossas graduações - duas de nós a vivenciamos sem as cotas sociais e raciais $^{3}$; uma de nós ingressou apenas no primeiro ano de implementação das mesmas. Da mesma forma, ainda eram incipientes outras políticas afirmativas, tal como o Prouni e o Reuni ${ }^{4}$. Muito além da dimensão macropolítica das ações instituídas, o plano micropolítico - habitat das forças e do sensível - também passou por mudanças profundas: o corpo estudantil é agora formado por presenças que antes praticamente não acessavam aquele espaço, e a reboque vieram diferentes problematizações. São presenças periféricas, pretas, indígenas, de classes sociais menos favorecidas do que aquelas que historicamente cursaram ensino superior, engendrando assim uma sala de 
aula mais diversa, multicultural $\mathrm{e}$ mutiterritorial.

Alunas, alunos e alunes interrogam mais os nossos lugares de poder de professoras, o conteúdo e as/os autores trabalhados. Não é mais apenas a aula de psicologia social que convida a pensar as questões do socius; são estudantes que trazem as questões por elas/es encarnadas suas experiências minoritárias, as violências sofridas, as barreiras para acessar e se manter na universidade - e, obviamente, o ardor de suas indignações. Não somos bem nós, as mestras, a buscar outras referências e observar nossos limites por livre e espontânea vontade: somos incitadas por um novo corpo estudantil que se faz escutar antes mesmo do período letivo ser iniciado. São, enfim, as/os alunas/os ou o anunciado encontro com elas/es que nos afeta e que nos convoca a transformar a nós mesmas.

Deparamo-nos, como em outras ocasiões, com os nossos bolsos furados ${ }^{5}$ : como se, ao tentar alcançar algo em nossos bolsos teoricamente cheios, não encontrássemos técnicas ou conceitos dos quais pudéssemos lançar mão para de dar conta daquilo que se nos apresenta (Souza, 2009). Como preparar as matérias a serem ministradas no semestre vindouro de maneira atenta a tais demandas, sem, ao mesmo tempo, ignorar nossa bagagem de saber/fazer? Que outros modos de dar aula poderiam ser inventados?

Em nosso trio, desejamos embarcar nesse trabalho sobre nós mesmas, aceitando o convite, por nós considerado amoroso, a um esgarçamento de nossas práticas docentes em psicologia social, problematizando conhecidas matrizes epistemológicas eurocêntricas - ainda que marginais num espectro amplo dessa área e pensando suas possibilidades de agenciamento com outros saberes, ainda menos visibilizados nas faculdades de psicologia.

Nossos aliados, Michel Foucault e Jorge Larrosa Bondía fortalecem uma acepção de experiência da qual partilhamos, isto é, como aquilo de que não se pode sair ileso: para o espanhol, ela necessariamente nos afeta; para o francês, ela pode ser tomada em sua potência transformadora. O referencial da Análise Institucional nos aporta com os instrumentos metodológicos dos diários de campo e das correspondências, dispositivos capazes de operar a passagem experiência-pensamento e que tanto servem à nossa proposta. Já num movimento de agenciamento com outras vertentes epistemológicas, encontramo-nos entusiasticamente com bell hooks ${ }^{6}$, com 
quem intensificamos a noção de transgressão como parceira de uma educação libertária.

Equipadas com esses e outros conceitos-ferramenta, atentas ao nosso entorno e dispostas a nos colocarmos em risco, montamos nosso problema, enunciamos nossa interrogação: como a nossa experiência de sala de aula na atual universidade pública pode contribuir para transgredir a própria prática docente e, na mesma toada, manter ou esgarçar o caráter aberto e minoritário de uma psicologia social alicerçada no paradigma éticoestético-político?

\section{Outras modulações para a docência em psicologia social}

Em princípios de 2019, as duas autoras deste artigo iniciavam o trabalho de docência em universidades públicas e, em posições ou cargos diferentes - uma substituta, uma adjunta - era necessário preparar disciplinas nunca antes por nós ministradas para turmas também desconhecidas. Construir planos de ensino nessas novas condições, além de estar em meio a grupos de colegas professores/as também desconhecidos/as em uma universidade nova, ainda que excitante, pode ser um tanto assustador. $\mathrm{O}$ início do semestre, então, trouxe consigo inúmeros desafios, dúvidas e inseguranças. Sentíamos o frio na barriga típico de uma estreia.

Num primeiro momento, foi a prerrogativa e a (auto)exigência de "ter que dar conta de tudo" que impulsionou a criação de nosso trio de comunicação: fomos rapidamente imersas na lógica do trabalho sequencial e demandadas a lidar com as dimensões institucional, pedagógica e teórica, tudo em um cenário de precarização e desvalorização da educação pública e com um tempo exíguo para o planejamento do período letivo, dado o momento já avançado em que tínhamos sido chamadas para assumirmos nossos cargos. Pareceu-nos tarefa impossível de ser feita de maneira solitária. Recorremos, então, umas às outras; em especial, as mais novas à professora mais experiente, em vias de se aposentar.

Mas havia um desafio particularmente complexo que se nos impunha e sabíamos bem que não era somente a nós, professoras recém chegadas: na universidade pública, o corpo discente - agora mais diversificado do que em nossos tempos de graduandas, graças a políticas afirmativas - vinha interpelando o corpo docente, demandando conteúdos e referências bibliográficas que fossem mais 
próximos às suas experiências pretas, periféricas, indígenas, femininas e feministas, LGBTQi+ ${ }^{7}$. Se já fazia parte de nossos repertórios e de nossos planos trabalhar com autoras/es e saberes locais contra-hegemônicos, era preciso reconhecer que muitos ainda eram europeus e brancos, por exemplo. O que isso significava? Não se tratava de diletantismo, insegurança de novatas, evitação de desgaste ou de "fazer constar" uma ou outra referência puramente próforma. Estávamos comprometidas em lançar uma mirada crítica a nós mesmas e à nossa formação - que, afinal, foi outra -, sem com isso ignorar nosso ethos e nossa bagagem epistemológica orientados por um paradigma ético-estético-político. Talvez (como veríamos mais adiante), a questão fosse justamente sustentar e intensificar tal direção.

O paradigma ético-estético-político refere-se não a uma "linha" ou "escola", e sim a determinado conjunto de saberes e práticas que podem ser reunidas sob um mesmo guarda-chuva epistemológico e metodológico, de matrizes filosóficas comuns ou, no mínimo, avizinhadas. Mais do que isso, trata-se de uma estratégia de produção de conhecimento, e, portanto, as dimensões ontológica e éticas também nele se atualizam (Silva, 2008).
A psicologia ancorada nesse paradigma tem, no Brasil, suas marcas históricas iniciadas nos anos 1970, em um clima que é, ao mesmo tempo, de autoritarismo e repressão sob as botas de ditaduras militares da América Latina e de um mundo ocidental que vive os efeitos do incandescente maio de 68 francês e das lutas de independência das colônias africanas. Um grupo de psis críticos e "indisciplinados" recusa o lugar de “guardiões da ordem” a que são chamados à época (Rodrigues, 2005) e, dentre eles, há aqueles que entram em contato com intelectuais libertários que visitavam o país na época e pouco mais tarde: Michel Foucault, René Lourau, Félix Guattari, dentre outros, advindos do movimento da Análise Institucional, da filosofia da diferença e do pensamento pósestruturalista. Guattari, cumpre evidenciar, apresentaria um "novo paradigma estético", em seu "Caosmose" (1992), anos depois. Esses contágios, combinados com outras contingências históricas, culminaram em apropriações-invenções singulares de uma psicologia social crítica, libertária, que imanentiza desejo, subjetividade e plano social e que ainda hoje ocupa um lugar um tanto marginal no cenário da psicologia brasileira. 
Diz-se desse paradigma "ético" porque comprometido não com normas nem com um sistema de verdades tomadas como prévias, ou como valor em si, ambos de ordem moral. Mas sim com princípios relativos ao modo como vivemos e estamos no mundo - confrontando "o que estamos pensando e dizendo com o que estamos fazendo, com o que estamos sendo" (Foucault, 2006). Ética como “o exercício do pensamento que avalia situações e acontecimentos, que afirma escolhas e caminhos como potencializadores de vida", nas palavras de Marisa Lopes da Rocha (2006, pg 171), isto é, atenta e rigorosa ao presente que experienciamos. Estético por estar preocupado em potencializar a criação: seja ela teórico-metodológica, seja ela existencial (de si), seja de mundo, já que criações singulares de sentidos a cada momento são "la única vía capaz de dar batalla al fascismo en todas sus dimensiones" (Guattari, 2009, p. 3). Político porque concebe ações e mundo numa relação de imanência, porque está associado com determinados posicionamentos e escolhas, porque constitui uma luta contra as forças que querem nos despotencializar (Rolnik, 1993), tanto na relação com o mundo, com os outros, quanto de nós conosco mesmos.
Este paradigma opera também uma lógica conectiva e rizomática (para usar um termo de Gilles Deleuze e Félix Guattari), uma vez que funciona a partir do princípio não da arborescência, da filiação ou da hierarquia, e sim da lateralidade, da descentralização e das alianças, recusando um lugar de verdade única e rechaçando especialismos. Deste modo, toma o fragmentário e o nômade como desejáveis e impulsiona o movimento de composição entre diferentes campos de conhecimento, intencionando borrar suas fronteiras (Silva, 2008).

Assim, colocou-se como questão para nós o que significaria, afinal, aceitar a reivindicação do corpo discente nessa nova universidade pública quando nós compartilhamos dessa estratégia de produção do conhecimento em psicologia social. Como preparar os programas das disciplinas de modo a incorporar o que nos era solicitado ao que já sabíamos e tínhamos a contribuir? Teríamos de encontrar a medida da ventilação dos nossos bolsos já furados.

Encontramo-nos, as três professoras, presencialmente, semanas antes do começo das aulas, e a partir daí decidimos seguir conversando através de ferramentas virtuais, considerando a distância entre nós. Almejando trocar sobre 
os programas das disciplinas, estratégias pedagógicas e maneiras de avaliar, adotamos como metodologia de trabalho a escrita de diários de campo coletivos e correspondências - tanto em forma de $e$ mails quanto por meio de um grupo em um aplicativo de conversas por telefone (o qual intitulamos “ideia”).

\section{Escrita-experimentação}

Ao escrever um diário de campo, segundo o referencial da Análise Institucional, um pesquisador tem a oportunidade de se relacionar de outra forma com a sua pesquisa, permitindo o conhecimento da vivência cotidiana de campo: não o "como fazer" das normas, mas o "como foi feito" da prática, nas palavras de René Lourau (1993, p. 77). Essa escrita compreende os embaraços, as dificuldades, os afetos, julgamentos e sensações daquele que pesquisa, refutando a noção de neutralidade. Acolhe os mais variados atravessamentos como material e parte importante de uma pesquisa.

A escrita se faz no calor da experimentação, ainda com as sensações vividas nas intervenções recentes pulsando no corpo. Como diz Remi Hess (2009, p. 76), "é o impulso emotivo que permite a entrada na prática do diário". Dessa forma, a escrita do diário é em si experimentação: experimentamos conceitos, ensaiamos e erramos, gaguejamos, numa espécie de brincadeira séria. Por não ser texto institucional, acadêmico, a ser publicado e avaliado, é uma escrita menos preocupada com preciosismos de linguagem e com a exatidão de "acertos" no uso de conceitos. Ainda assim, ela pode se tornar combustível para a escrita e a pesquisa, inclusive a acadêmica.

$\mathrm{Na}$ contramão de um dispositivo rígido, com limites bem definidos, o diário possui uma plasticidade que nos permite criar diferentes usos e funções. Por estarem forjados a muitas mãos e por fazermos um uso compartilhado de suas linhas, demoslhes o nome de diários coletivos - e talvez Rémi Hess e Gabriele Weigand (2006) também assim os chamassem. Para nós, trata-se de mais do que relatos, descrições de um cotidiano; engendram-se pensamentos, análises, encaminhamentos, estratégias de intervenções que traduzem práticas inventivas, inacabadas, perecíveis.

Ao mesmo tempo em que os estudantes escreviam seus diários de aprendizagem, Rémi Hess escrevia seu diário pedagógico que era, simultaneamente, um diário de pesquisa. Da mesma forma, em nosso caso, ao passo em que mantivemos os nossos diários 
docentes - individuais e coletivos propusemos às/aos alunas/os que escrevessem seus diários discentes.

Ao fazermos registros das aulas, desde aquilo que acontecia diante de nossos olhos até aquilo que era possível de ser percebido por outros sentidos, construímos uma ferramenta de acompanhamento e análise do nosso próprio trabalho. Olhando para uma metodologia que não funcionou, ou para uma forma avaliativa que deu certo com alguma turma, conseguimos modular algumas estratégias de sala de aula para as próximas vezes que ministrássemos as mesmas disciplinas. $\mathrm{Na}$ troca de mensagens em nosso trio, passamos então a compartilhar os nossos registros individuais, pretendendo interferir umas nas práticas das outras, compondo coletivamente estratégias que pudessem fortalecer os processos de formação que se inventavam no percurso de cada uma.

Já para as/os alunas/os, incentivamos que registrassem ali, fosse um diário de campo do estágio, ou um diário/caderno de uma disciplina, não somente os acontecimentos ou conteúdos, mas também - e principalmente - suas percepções, sensações e reflexões. Desse modo, o diário funciona como uma outra superfície para ajudar na elaboração de problemáticas, um espaço de reflexão crítica, autoria e articulação entre conceitos e suas realidades, para além da bibliografia e das discussões em aula. E no momento da troca dos conteúdos - ou mesmo de trabalhos feitos em grupos -, também se efetua um vetor de coletivização dessa prática entre alunas/os.

Por ser uma ferramenta que permite um acompanhamento longitudinal, o diário contribui para construir com a turma um semestre que seja menos voltado às avaliações e à nota final, e mais preocupado, portanto, com um ensino processual, singular e atravessado pelas suas experiências. Dessa forma, o diário serve como outra proposta pedagógica que pode operar na intersecção entre teoriaprática e pensar-sentir. Ao sustentar essa ferramenta enquanto metodologia de pesquisa e ensino, marcamos uma concepção de processo de aprendizagem que ocorre pela via da experiência.

A prática epistolar, por sua vez, também infiltrou nossas salas de aula. Em Pelotas, foi proposto que alunas/os da disciplina de psicologia e educação escrevessem cartas sobre suas experiências do aprender, com autoria ou anonimamente (como desejassem). Tais cartas tiveram como destinatárias/os estudantes da licenciatura em psicologia no Rio de 
Janeiro e foram lidas e discutidas coletivamente em aula. A turma, por sua vez, redigiu suas respostas, escritas já afetadas pelas cartas recebidas do Sul e agenciadas às suas próprias vivências e articulações com o que vínhamos trabalhando ao longo do período. Esta correspondência radicalizou a coletivização e ampliação de um processo formativo entre muitos - estudantes, professoras, universidades.

Vai ficando evidente como a experiência aqui ocupa um lugar transversal em nosso trabalho: é território de onde brotam as questões-incômodos que mobilizam e movimentam nossos corpos, nossas práticas docentes e nossa escrita, e é também plano em que se efetuam experimentações e propostas inclusive para a escrita das/os alunas/os. Emparceiramo-nos a Michel Foucault e Jorge Larrosa Bondia para intensificar essa formulação que tanto nos é cara.

Conforme Foucault (2010), a experiência pode ser compreendida em sua acepção transformadora, isto é, aquela que pode tanto servir de ponto de partida para uma problematização quanto constituir o próprio processo de escrita e aposta do trabalho, o que é o nosso caso. "Sou um experimentador, e não um teórico (...) no sentido de que escrevo para mudar a mim mesmo e não mais pensar a mesma coisa de antes", diz ele (2010, p. 290), deixando entrever uma acepção de sujeito que é processual, indissociável do mundo, em constante relação de coprodução com este.

No que tange a articulação escritaexperiência que propomos, portanto, não se trata de meramente relatar coisas tal qual elas ocorreram, de maneira fiel a uma verdade dos fatos, mas sim de tomar as experiências como pontos de partida para a problematização daquilo que é “considerado dado, coerente, óbvio, lógico, previsível, evidente, funcional ou nobremente científico" (Rodrigues, 2005a, p.18-19). A própria problematização, assim, também se oferece à coletivização, na medida em que possa afetar quem tenha contato com ela e ao campo de saber e de práticas correspondente. Uma

experiência é alguma coisa que fazemos inteiramente sós, mas só podemos fazê-la na medida em que escapará à pura subjetividade, em que outros poderão, não digo retomá-la exatamente, mas, ao menos, cruzá-la e atravessá-la de novo (Foucault, 2010, p. 295).

Sintonizado com o Foucault, Bondia (2002) afirma que a experiência “é 
a passagem da existência, a passagem de um ser que não tem essência ou razão ou fundamento, mas que simplesmente "existe" de uma forma sempre singular, finita, imanente, contingente" (p.25). O autor define a experiência como algo que nos passa, nos toca, diferente daquilo que se passa, alheio a nossos corpos. Para ele, o sujeito da experiência é aquele que está aberto aos sentidos porvir, atento ao seu entorno. É incapaz de experiência aquele que não se expõe, isto é, quem não se coloca em risco, não se afeta.

Desta feita, propomos nos posicionar fora do que está colocado, menos para nos retirar, senão para inventar outros lugares para habitarmos a docência. Utilizando-nos do mesmo prefixo, sugerimos fazer excursões: sair do curso previsto para discutir outras práticas de ensino, possíveis e necessárias e, para quem sabe, transgredir a sala de aula.

Para então escapar dos já conhecidos pólos ciência/técnica perspectiva positiva e retificadora - e teoria/prática - perspectiva política e crítica, Bondia (2002) sugere pensar a educação a partir do par experiência/sentido. Tal escolha é por ele justificada ao afirmar que "pensar não é somente 'raciocinar' ou 'calcular' ou 'argumentar', como nos tem sido ensinado algumas vezes, mas é sobretudo dar sentido ao que somos e ao que nos acontece" (p.21).

Por essa outra perspectiva das práticas educativas, Bondia por sua vez alinha-se com bell hooks e Paulo Freire, sublinhando a indissociabilidade entre sentir, experienciar, pensar e aprender. Tais autores-professores marcam a necessidade de conectarmos a aula com tudo o que acontece fora dela, de forma a darmos visibilidade a vida dos/as alunos/as e da/o professor/a que compõem a turma.

Por essa via, desejamos desviar do método conteudista, que privilegia a aquisição de informação, e de uma formação puramente tecnicista - onde as aulas presenciais poderiam ser facilmente substituídas pelo ensino à distância ${ }^{9}$ visando recuperar a ligação entre as práticas de vida, os hábitos de ser e os papéis profissionais, de forma que possa ser a partir das experiências pessoais e coletivas que os sentidos da/na sala de aula sejam criados. À vista disso, fomentamos um caminho que descentraliza nossa mente como fonte e receptáculo do ensinoaprendizagem: para além de um aspecto cognitivo, indicamos um aspecto sensorial, que ao invés de se restringir ao "conteúdo aplicado", incentiva que a memória 
experiencial e os afetos possam aparecer e compor com o ensino.

\section{Pistas para uma educação libertária}

Foi precisamente pelo momento em que nossa experiência de docência se encontra - povoado por uma diversidade de cores e culturas na sala de aula - que o livro de bell hooks, Ensinando a transgredir: a educação como prática de liberdade, ecoou fortemente nas discussões que fazíamos em nosso trio sobre os desafios de um ensino que se proponha a trabalhar com o reconhecimento das diferenças de forma crítica e ética. Para transgredir o ensino conteudista, onde o prazer é deixado do lado de fora da aula e o aprendizado reforça os sistemas de dominação da sociedade, compartilhamos a seguir algumas das pistas deixadas pela autora.

Um dos maiores desafios para uma pedagogia libertadora, segundo bell hooks, é a construção de uma comunidade engajada. Isso exige da/do docente uma atenção para estar sempre no momento presente, uma vez que "a sala de aula nunca é a mesma" (hooks, 2017, p.211); um compromisso que leva em seu bojo a disposição a ser responsável. Sendo assim, uma pedagogia que seja engajada enfatiza a participação de todas/os, de forma a criar diferentes metodologias e dispositivos para que cada voz seja ouvida.

Outro ensinamento que vai ao encontro da pedagogia engajada é provocar estudantes para pensar criticamente, e afirma hooks (2020) que o cerne do pensamento crítico é o anseio por saber. Para a autora, esse anseio só existe quando a/o aluna/o pode vislumbrar a/o professor/a comprometida/o com um conhecimento que visa desmontar as diversas formas de opressão da nossa sociedade. Enquanto uma mulher negra que estudou durante e após o regime do apartheid, ela conta que nas escolas com integração racial, ainda atravessadas pelo racismo, "o conhecimento passou a se resumir à informação" (hooks, 2017, p.12); teria sido aí, para ela, que se perderam o entusiasmo e o prazer no processo formativo.

Nesse sentido, nosso empenho por fazer da sala de aula um lugar prazeroso diz menos de criar um ambiente onde não haja discórdias e mais de um ensino que possibilite uma construção de conhecimento a favor de práticas de liberdade, ou ainda, uma educação que possa transgredir com as formas de aprisionamento dos modos de ser e de pensar. Recuperar o entusiamo então, desde nosso lugar, que não é o de 
professoras negras no período do apartheid, mas o de professoras brancas em 2020, na universidade pública brasileira, está relacionado a não perder de vista o próprio caráter desnaturalizante, contrahegemônico e múltiplo da psicologia social ancorada no paradigma ético-estéticopolítico.

Pensar o ensino em sua relação com a prática de liberdade é, portanto, o horizonte de uma pedagogia anticolonial, crítica e feminista, segundo bell hooks. Em diálogo com as ideias de Paulo Freire, hooks age com "a convicção de que é possível dar aula sem reforçar os sistemas de dominação existentes", como o racismo e o sexismo, ao mesmo tempo que propõe novas formas de ensino considerando uma turma de alunos diversificados (2017, p.31). Entre os diversos desafios colocados ao ensino em uma sala de aula multicultural, perguntamo-nos "como poderemos ensinar para culturas diferentes da nossa, sem colonizá-las?" (Veiga-Neto, 2002, p.48). Ou ainda, como transmitir um currículo que não ensine as/os alunas/os a falarem a língua do opressor (hooks, 2017)?

Descolonizar o conhecimento passa por descentralizar as epistemologias ocidentais-brancas-europeias da construção do saber de forma a inserir na formação outras perspectivas, a saber: ameríndia, africana, latina, entre outras, visando a construção de uma transdisciplinaridade decolonial (Maldonado-Torres, 2016) e uma epistemologia decolonial (Walsh, 2007). A problemática segue atual sem que, no entanto, seja nova. Na década de 90, o educador brasileiro Paulo Freire já chamava a atenção para a importância dessa questão.

O clamor pelo reconhecimento da
diversidade cultural, por repensar
os modos de conhecimento e pela
desconstrução das antigas
epistemologias, bem como a
exigência concomitante de uma
transformação das salas de aula, de
como ensinamos e do que
ensinamos, foram revoluções
necessárias - que buscam devolver
a vida a uma academia moribunda e
corrupta. (Freire, 2019, p. 45).

Revoluções que seguem sendo necessárias à medida que afirmamos o compromisso com a criação de uma universidade culturalmente diversa e uma psicologia social em constante vias de feitura e atualização. Uma necessidade que seguirá existindo enquanto formos diariamente bombardeados/as por forças de 
subjetivação colonizadoras (e portanto, nos referimos aos planos macro e micropolítico), desde a história da "descoberta do Brasil" - ainda narrada assim em muitos livros didáticos passando por teorias ensinadas na universidade que desconsideram os saberes não hegemônicos ou os classificam como inferiores.

Quando começamos a reconhecer nossa herança colonialista, patriarcal e heteronormativa nas diferentes dobras de nossas vidas - seja no plano do que é visível, dizível, palpável, seja no plano do sensível, afetivo, das forças compreendemos que, até mesmo de forma inconsciente, podemos reproduzir práticas que excluem determinados modos de ser e estar no mundo. Desta feita, é preciso estar sempre atentas/os às configurações da sala de aula no momento presente (hooks, 2017) e constantemente perguntar-se sobre os pontos cegos da nossa forma de pensar e agir.

Reconhecer e trabalhar com as diferenças exige disposição para ver a sala de aula mudar bem como para ver as transformações em nós mesmas. Como efeito, podem ocorrer mudanças nas relações entre as/os alunas/os e também na relação do professor/a com a turma. Estar disponível então implica estar atenta/o de forma crítica, permanecer paciente e vigilante, para compreender, como diz hooks (2020), como a diferença se articula politicamente na nossa vida.

\section{Ventilar os bolsos}

Frente à convocação das/os discentes de uma outra universidade pública - onde era preciso rever nossas epistemologias e metodologias - recusamos os lugares de reatividade, individualização e conteudismo. Assumimos nossos bolsos furados e ocupamo-nos de um duplo movimento: pensar e criar modos de transgredir a própria prática docente e ampliar o caráter aberto e minoritário de uma psicologia apoiada no paradigma ético-estético-político.

Apostamos em uma docência que é costurada paulatinamente no exercício de uma coletivização que se faz tanto com os/as alunos/as quanto entre nós, professoras. A feitura dos diários coletivos e os nossos encontros presenciais são em si mesmo práticas transgressoras na medida em que produzem importantes deslocamentos em nós e rompem com a lógica individualista, competitiva e normatizadora da instituição universidade. Posicionamo-nos também no ensejar e aprender. Mais do que um apoio teórico- 
técnico que oferecemos umas às outras, compartilhando bibliografias e estratégias didáticas, nossa metodologia aponta para um movimento de formação que é contínuo, partilhando dúvidas e questões com as quais nos defrontamos em sala de aula: um formar se formando.

Em nossa ideia, tecemos análises e reflexões entre áudios rápidos e entusiasmados (enviados após alguma dinâmica ou dispositivo que funcionou), longos e-mails e elaborações que ganharam corpo em trabalhos apresentados em eventos acadêmicos. Ao longo desse percurso, reencontramos ferramentas e criamos outras que passaram a dar maior sustentação a nossos bolsos agora ventilados.

Alinhadas a bell hooks, nossa pretensão não foi a de propor modelos para transformar a sala de aula ou a prática docente, e sim construir e exercitar uma postura ético-política que dê passagem a estratégias sempre momentâneas, locais, singulares, constantemente modificadas e inventadas, pois cada espaço, grupo e experiência de ensino é diferente. Precisamente por essas razões, quando elaboramos nossos planos de ensino, ainda que tenhamos estudado muito e nos esforçado para preparar as aulas e as estratégias didáticas, mantivemos programas suficientemente abertos, como os desejáveis bolsos arejados.

A aposta é, portanto, na construção de uma comunidade engajada, na possibilidade de criações, composições e agenciamentos com aquilo que vai se apresentando a cada momento em nosso cotidiano docente. Ao lado de bell hooks, nos colocamos em um caminho docente que anda na contramão de um ensino onde o conteúdo se resume à informação, o pensamento crítico é desincentivado e a diferença achatada; visamos assim transgredir com o aprisionamento de modos de ser e pensar ao assumirmos um compromisso ético que favorece práticas de liberdade.

Além de lançar um olhar sobre as teorias que estamos ensinando, nos atentamos para a forma como ocupamos a posição de docentes. Nossa orientação segundo o paradigma ético-estéticopolítico, com toda a sua direção de coletivização e descentralização, não impede que o lugar de professoras - que, afinal, é um lugar de poder - reproduza autoritarismos e opressões em alguma medida, mesmo que sem tal intenção. Desta feita, também para a psicologia social da qual partilhamos se fez necessário formular novas propostas pedagógicas que permitissem 
transversalizar as relações da sala de aula em nosso presente.

De outro lado, percebemos que não havia exatamente um rompimento a ser feito com a psicologia social alicerçada no paradigma ético-estético-político, e sim uma exacerbação do seu caráter aberto e minoritário. Afinal, uma vez que esse paradigma não almeja um status de verdade absoluta, imutável, e pressupõe a constante produção de si próprio e do mundo, são mais que bem-vindas as alianças com outras/os autoras/es minoritários, contra-hegemônicos, que descentralizam saberes eurocêntricos, brancos, cisnormativos, e contribuam para uma epistemologia decolonial - sem perdermos, é claro, o cuidado e a coerência conceitual. Se encontramos oposição a essa abertura é pela dureza com que esse viés possa estar sendo apropriado. A psicologia social de paradigma ético-estético-político só toma matizes colonizadoras e universalizantes se a relação com as/os suas/seus autoras/es trai seu próprio princípio, que não é o de mestria e filiação (lógica arborescente), mas o de emparceiramento, lateralidade e agenciamento (lógica rizomática). De acordo com seus próprios pressupostos, não se trata de uma linha ou "escola" a ser seguida, e sim uma estratégia de produção de conhecimento cujo princípio passa pela dissolução de fronteiras entre campos de conhecimento. Foi assim com as apropriações-invenções à brasileira na década de 1970 e não haveria porque deixar de sê-lo hoje.

Visto que essa psicologia social acompanha os movimentos do presente, nada mais justo que aceitar esse desafio e acolher as interrogações que este nos coloca - questões que a sala de aula mais diversa, multicultural e mutiterritorial nos apresenta através das presenças pretas, periféricas, indígenas, que interpelam os limites do nosso olhar. Entendemos, pois, que inserir no ensino outras perspectivas tais como, ameríndia, africana, latina - é justamente cumprir com o caráter disruptivo, inventivo e conectivo da psicologia social que pretendemos transmitir.

É nesse sentido que essa estratégia de produção de conhecimento com a qual nos emparelhamos está em sintonia com a concepção de experiência que sustentamos juntas a Foucault e Larrosa. Esta prevê que estejamos sempre dispostas/os, abertas/os para a realidade que se apresenta, num jogo ético e rigoroso. Não se trata de um relativismo, mas de uma outra concepção de rigor que acompanha esses processos imanentes de forma a se transformar junto 
a eles: mais que a mera transformação da realidade, a realidade como transformadora de nós.

As perguntas que moveram este trabalho podem por fim retornar: o que o presente tem a contribuir para uma determinada psicologia social? Que transgressões e ampliações são possíveis tanto das práticas docentes em sala de aula quanto da própria psicologia social transmitida?

Evitamos cair na tentação de preencher ou remendar nossos bolsos furados. Demo-nos conta de que queremos que nossos bolsos permaneçam arejados, pois é só assim que podem circular os ventos da invenção de outras práticas de formação em psicologia social (Souza, 2009). Revertemos a impressão de que tudo o que havia em nossos bolsos nos escapava pelos furos e percebemos que algo de nossa formação - não aquela da formalidade instituída de conteúdos e técnicas a serem replicadas, mas aquela ética - já trazia consigo premissas valiosas a serem rejuvenescidas. O desafio, assim, foi e é o de recobrar o passo e caminhar com bolsos nem vazios nem herméticos: bolsos ventilados.

\section{Referências}

Bondia, Jorge Larrosa. (2002). Notas sobre a experiência e o saber da experiência. Revista Brasileira de Educação. Rio de Janeiro, (19), 2028. Recuperado de https://www.scielo.br/pdf/rbedu/n19/ $\underline{\text { n19a02.pdf }}$

Deleuze, Gilles \& Guattari, Félix. (1997). Mil platôs - capitalismo e esquizofrenia. Vol. 1. São Paulo: Editora 34.

Foucault, Michel. (2006). Política e ética - uma entrevista (1984). Ditos $e$ Escritos V: Ética, Sexualidade, Política (pp. 218-224). Rio de Janeiro: Forense Universitária.

Foucault, Michel. (2010). Conversa com Michel Foucault (1980). Ditos e escritos VI: Repensar a Política (pp. 285-347). Rio de Janeiro: Forense Universitária.

Freire, Paulo. (2019). Pedagogia da Autonomia: saberes necessários à prática educativa. Rio de Janeiro/São Paulo: Paz e Terra.

Guattari, Félix. (1992). Caosmose: um novo paradigma estético. São Paulo: Editora 34.

Guattari, Félix. (2009) Les années d'hiver: 1980-1985. Paris: Les Prairies Ordinaires.

Hess, Rémi. (2009). O momento do diário de pesquisa na educação. Ambiente \& Educação, v.14, 61-87. Recuperado de https://periodicos.furg.br/ambeduc/ar $\underline{\text { ticle/view/1137 }}$

Hess, Rémi. \& Weigand, Gabriele. (2006). A escrita implicada. Cadernos de Educação, Reflexões e Debates, n.11, pp. 14-25. Recuperado de 
https://pt.scribd.com/document/1754 82469/A-Escrita-Implicada-RemiHess-e-Gabriele-Weigand

hooks, bell. (2017). Ensinando a transgredir: a educação como prática de liberdade. Tradução de Marcelo Brandão Cipolla. 2ed. São Paulo: Editora wmf Martins Fontes.

hooks, bell. (2020). Ensinando pensamento crítico: sabedoria prática. Tradução Bhuvi Libanio. São Paulo: Elefante.

Lourau, René. (1993). Análise Institucional e Práticas de Pesquisa. Rio de Janeiro: UERJ.

Maldonado-Torres, Nelson. (2016). Transdisciplinaridade e decolonialidade. Sociedade E Estado, 31(1), 75-97. Recuperado de https://periodicos.unb.br/index.php/s ociedade/article/view/6080

Rocha, Marisa Lopes da. (2006) Psicologia e as práticas institucionais: A pesquisaintervenção em movimento. Revista Psico, 37(2), 169-174. Recuperado de

https://revistaseletronicas.pucrs.br/oj s/index.php/revistapsico/article/view/ $\underline{1431}$

Rodrigues, Heliana de Barros Conde. (2005). A psicologia social como especialidade: paradoxos do mundo psi. In: Revista Psicologia \& Sociedade; 17 (1), 17-28. Recuperado de https://www.scielo.br/scielo.php?scri $\mathrm{pt}=\mathrm{sci}$ arttext\&pid=S0102-

$71822005000100013 \& \operatorname{lng}=$ en\&nrm= iso\&tlng $=\mathrm{pt}$
Rodrigues, Heliana de Barros Conde. (2005a). Para desencaminhar o presente Psi: biografia, temporalidade e experiência em Michel Foucault. In N. M. F. Gurareschi \& S. M. Hüning (orgs.). Foucault e a Psicologia (pp. 7-30). Porto Alegre: Abrapso Sul.

Rolnik, Suely (1993). Pensamento, corpo e devir: uma perspectiva ético/estético/política no trabalho acadêmico. Cadernos de Subjetividade, 1(2), 241-251. Recuperado de https://revistas.pucsp.br/index.php/ca dernossubjetividade/article/view/381 $34 / 25870$ DOI: https://doi.org/10.2354/cs.v1i2.38134

Silva, Rosane Neves da. (2008). Ética e paradigmas: desafios da psicologia social contemporânea. In: K. S. Ploner, L. R. Ferreira, M. L. M. Schlindwein \& P. A. Guareschi (Org). Ética e paradigmas na psicologia social [online] (pp. 3945).

Souza, Alice de Marchi Pereira de. In(ter)ventar: encontros possíveis entre psicologias e juventudes. 2009. 173f. Dissertação (Mestrado em Psicologia) - Instituto de Ciências Humanas e filosofia. Programa de Pós-Graduação em Psicologia, Universidade Federal Fluminense, Niterói, 2009.

Universidade do Estado do Rio de Janeiro. Sistema de cotas. Recuperado de www.uerj.br:a-uerj:a$\underline{\text { universidade:sistema-de-cotas }}$

Veiga-Neto, Alfredo. (2002). Cultura e Currículo. Contrapontos, (4), 43-51. Recuperado 
https://siaiap32.univali.br/seer/index. php/rc/article/view/133/113

Walsh, Catherine. (2007) ¿Son posibles unas ciencias sociales/culturales otras? Reflexiones en torno a las epistemologías decoloniales. Nómadas; N.26, 102-113. Recuperado de https://www.redalyc.org/pdf/1051/10 $\underline{5115241011 . p d f}$

\footnotetext{
Notas

${ }^{1}$ Ambas são autoras deste artigo.

2 Gislei Domingas Romanzini Lazzarotto, professora aposentada do Departamento de Psicologia Social e Institucional do Instituto de Psicologia da UFRGS.

${ }^{3}$ A Lei $n^{\circ} 12.711 / 2012$, sancionada em agosto deste ano, garante a reserva de 50\% das matrículas por curso e turno nas 59 universidades federais e 38 institutos federais de educação, ciência e tecnologia. Regulamentada pelo Decreto $\mathrm{n}^{\mathrm{o}} 7.824 / 2012$, essa lei propõe $25 \%$ das vagas para estudantes oriundos da rede pública com renda igual ou inferior a 1,5 salário mínimo, 25\% para candidatos que estudaram integralmente no ensino médio e que possuem renda igual ou superior a 1,5 salário mínimo e, ainda, um percentual para pretos, pardos e indígenas. No âmbito do estado do Rio de Janeiro, a lei de cotas $\mathrm{n}^{\circ} 3708$ foi aprovada em 2001 e prorrogada por no mínimo dez anos em 2018, pela lei $\mathrm{n}^{\circ} 8121$ (Universidade do Estado do Rio de Janeiro, 2020).

${ }^{4}$ Com vistas à democratização do acesso à Educação Superior foi criado o PROUNI Programa Universidade Para Todos, instituído pela Lei no 11.096 de 13 de janeiro de 2005 -e o REUNI - Programa de Apoio a Planos de Reestruturação e Expansão das Universidades Federais, pelo decreto $\mathrm{n}^{\circ} 6.096$ de 24 de abril de 2007.

${ }^{5}$ A expressão "bolsos furados" foi cunhada por estagiárias do projeto de extensão Estação PSI, da Universidade Federal do Rio Grande do Sul, que foi coordenado pela professora Gislei Lazzarotto. Acabou se tornando recorrente entre muitas extensionistas que passaram pelo
}

projeto, como as duas autoras deste artigo, e usado em suas produções posteriores.

6 A autora escreve seu nome em letras minúsculas na intenção de destacar o que ela escreve, e não a sua pessoa. Por respeito à opção da autora, decidiu-se manter a grafia com que ela se identifica.

7 Ainda que não estejam previstas, por lei, cotas para a população LGBT na graduação, as questões de gênero também (re)ganharam amplitude nos últimos anos como tema necessariamente transversal a toda a psicologia.

8 "A única via capaz de fazer frente ao fascismo em todas as suas dimensões". Tradução nossa.

9 Durante a escrita do presente trabalho passamos pela pandemia do novo coronavírus, o que acarretou na suspensão das aulas presenciais e implementação do ensino remoto em caráter emergencial e temporário. Ainda que isso não seja sinônimo de um ensino puramente tecnicista e que há também esforços para reinventar a sala de aula nesse formato, num primeiro momento essa adaptação parece trazer inúmeras perdas para quem sempre apostou nos acontecimentos que surgem do encontro de corpos em sala de aula e em tantos outros atravessamentos que só são possíveis em presença.

Alice De Marchi Pereira de Souza é professora adjunta do Instituto de Psicologia/Departamento de Psicologia Social e Institucional/UERJ.

E-mail: alicedemarchi@gmail.com

ORCID: http://orcid.org/0000-0002-7606$\underline{9966}$

Karine Shamash Szuchman é mestra em Psicologia Social e Institucional pela UFRGS.

E-mail: karineszuchman@ gmail.com ORCID:https://orcid.org/0000-0003-3136$\underline{6366}$

Submissão: $22 / 10 / 2020$

$1^{\circ}$ avaliação: $20 / 11 / 2020$ Aceite: $17 / 12 / 2020$ 